\title{
Chiseling of Exposed Bone to Stimulate Granulation Tissue after Mohs Surgery
}

EVELYN E. VANDERVEEN, M.D. JOHN G. STONER, M.D.

NEIL A. SWANSON, M.D.

Abstract. Extensive Mohs surgery for carcinomas of the forehead and scalp occasionally requires the removal of periosteum. The exposed bone presents a wound management problem. One method, if healing by secondary intention is a viable option, is to chisel bone to stimulate granulation tissue and promote healing. A case is presented that describes this procedure in an elderly patient.

When Mohs surgery is required for carcinomas of the forehead or scalp, the resulting defect may be allowed to heal by secondary intention, immediately reconstructed by means of skin flaps or grafts, or reconstructed in a delayed fashion after secondary intention healing. ${ }^{1}$ If the defect is large or from a recurrent or aggressive carcinoma, healing by secondary intention may be preferable, enabling close observation to detect recurrence. Secondary intention healing may also be indicated in elderly patients who cannot tolerate further reconstructive surgery. ${ }^{2}$

However, in large full-thickness defects with exposed bone, healing by secondary intention is a slow process since epithelialization proceeds only from

Evelyn E. Vanderveen, M.D., is Chief Resident of Dermatology, Department of Dermatology, University of Michigan Medical School, Ann Arbor.

John G. Stoner, M.D., is Clinical Assistant Professor of Dermatology, Johns Hopkins University, Baltimore.

Neil A. Swanson, M.D., is Assistant Professor of Dermatology and Otolaryngology-Head and Neck Surgery, Director, Mohs Surgery Unit, University of Michigan Medical School, Ann Arbor.

Address reprint requests to Evelyn E. Vanderveen, M.D., Department of Dermatology, C2071 Outpatient Building, Box 031, University of Michigan Medical School, Ann Arbor, MI 48109. the edges of the defect. ${ }^{3} \mathrm{~A}$ bed of viable granulation tissue is also required to serve as a matrix for epithelial migration. When a defect involves exposed bone, chiseling of the exposed bone can stimulate the formation of a granulation tissue wound base and promote healing. The following case presentation illustrates this procedure.

\section{CASE REPORT}

A 76-year-old woman presented with a recurrent 4$\times 5-\mathrm{cm}$ basal-cell carcinoma on the left upper forehead (Fig. 1). The carcinoma was extirpated using

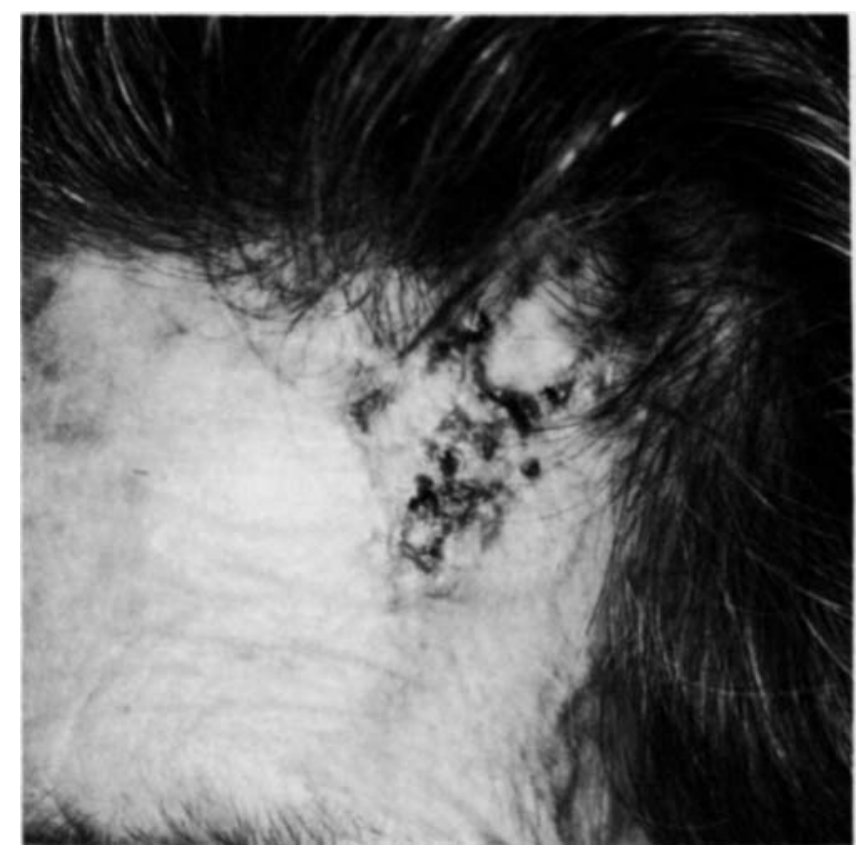

FIGURE 1. Recurrent basal-cell carcinoma on left upper forehead. 


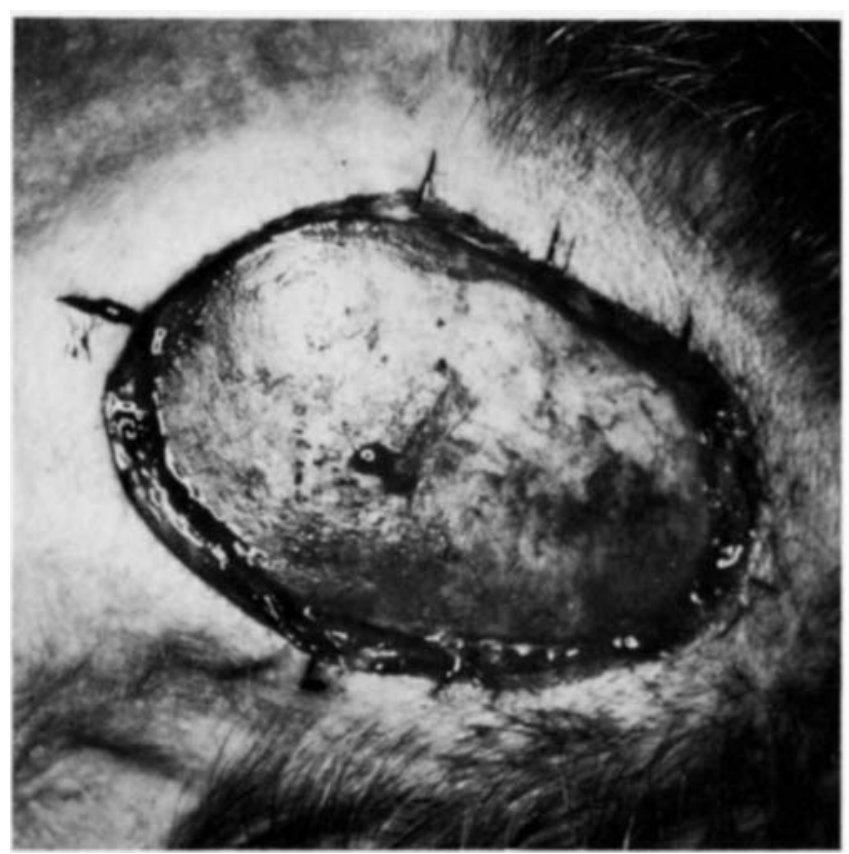

FIGURE 2. Surgical defect following removal of periosteum.

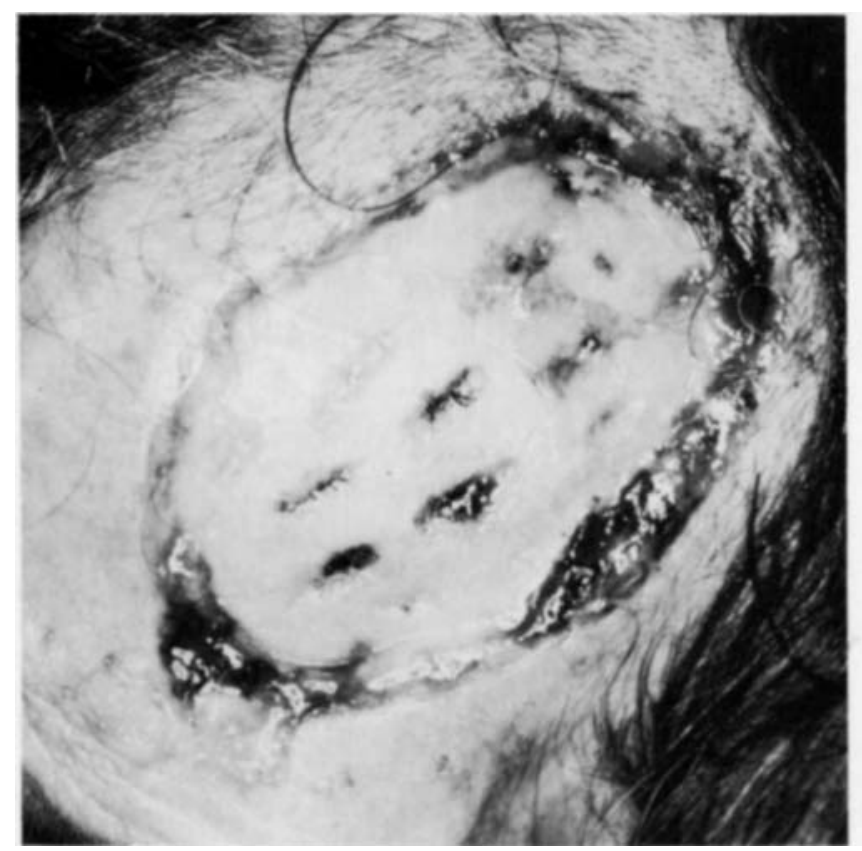

FIGURE 4. Granulation tissue is evident in the chiseled areas and at the wound margins 3 weeks postoperatively.

Mohs surgery fresh-tissue technique. During the final stage, a portion of periosteum was removed leaving exposed but uninvolved cranium. The final surgical defect (measuring $6 \times 8 \mathrm{~cm}$ ) is shown in Figure 2. Multiple areas of exposed bone were then chiseled, producing small bleeding points (Fig. 3).

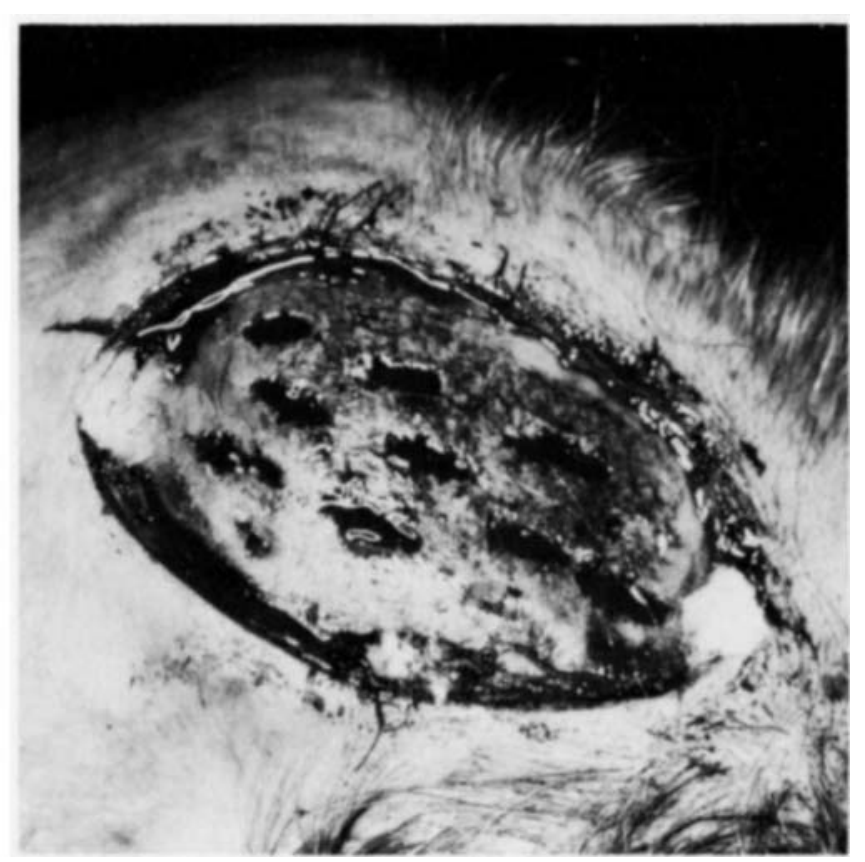

FIGURE 3. Appearance of the wound after chiseling of the cortex to produce bleeding points.

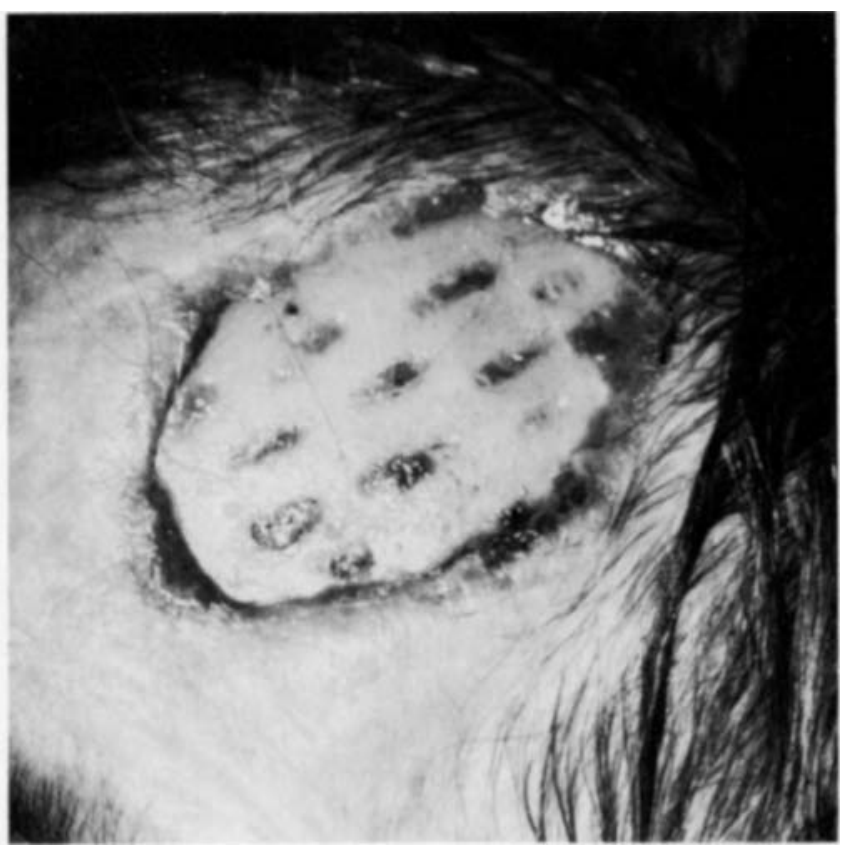

FIGURE 5. At 5 weeks postoperatively, additional granulation tissue is present.

Wound care consisted of daily cleansing with hydrogen peroxide followed by application of bacitracin ointment. Within 3 weeks, granulation tissue was present in the chiseled areas as well as at the wound periphery (Fig. 4). At 5 weeks postoperatively, further granulation tissue was evident (Fig. 5). At 7 weeks, the entire wound was covered with 


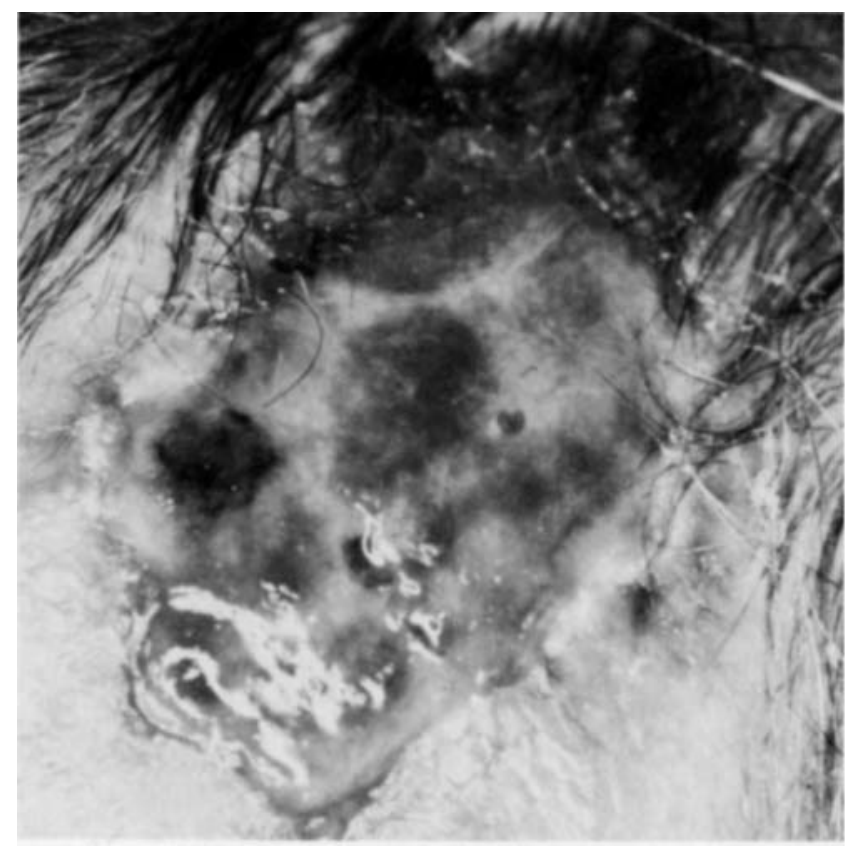

FIGURE 6. Complete coverage of the wound with granulation tissue at 7 weeks postoperatively.

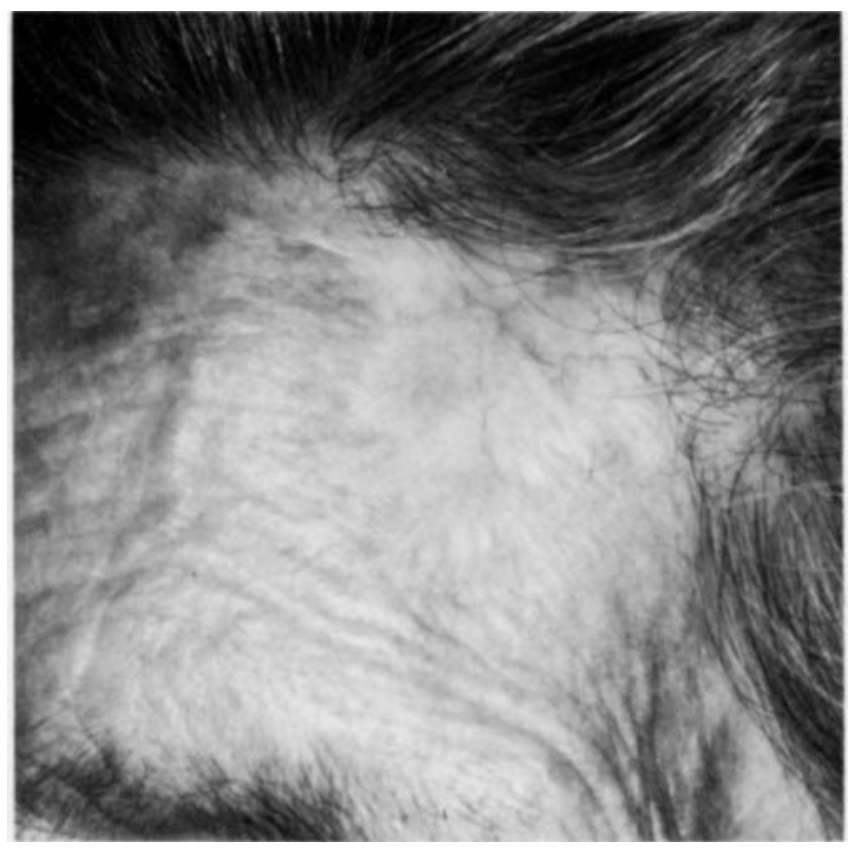

FIGURE 8. Appearance 36 weeks postoperatively.

granulation tissue (Fig. 6). By 16 weeks postoperatively, the wound was completely healed (Fig. 7). A very acceptable cosmetic result was subsequently obtained as evidenced by the patient's appearance at 36 weeks postoperatively (Fig. 8).

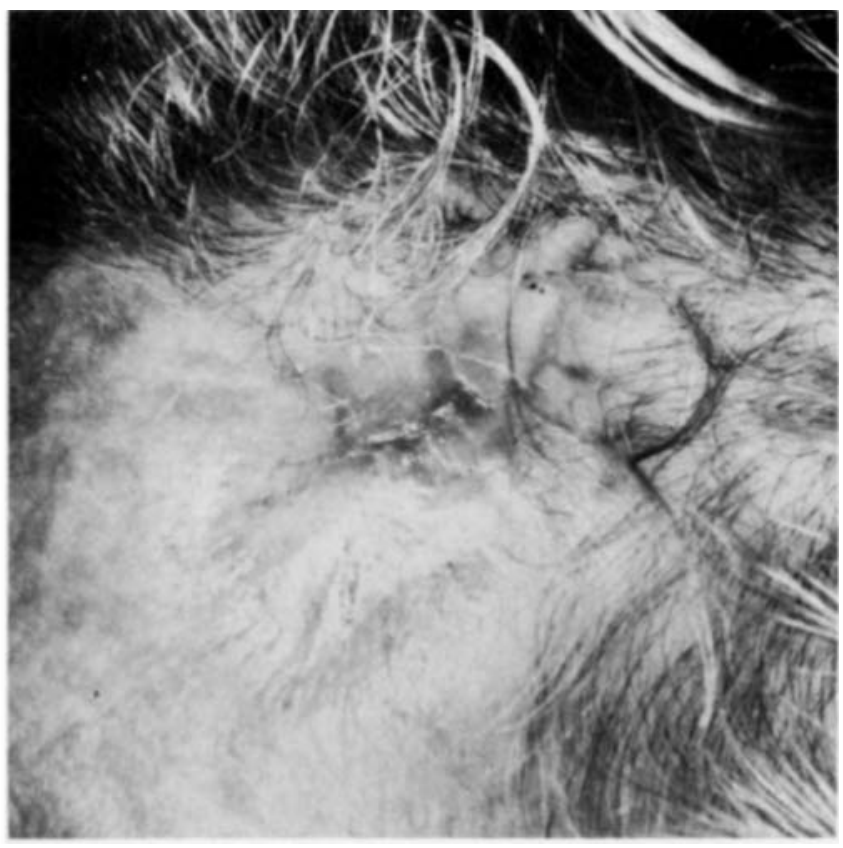

FIGURE 7. Appearance 16 weeks postoperatively following extensive wound contraction.

\section{COMMENTS}

Mohs noted the benefit of excising portions of exposed bone with a rongeur or chisel to stimulate granulation tissue after using the fresh-tissue technique. ${ }^{4}$ Bloom also documented three cases of aggressive recurrent basal-cell carcinoma of the forehead and scalp that required removal of the entire thickness of the skin and periosteum because of tumor involvement. Healing occurred by secondary intention after gentle chiseling of the outer table of the bone to microbleeding points. There were no complications and the cosmetic results were good. ${ }^{5}$ In addition, Ceilley and coworkers noted that since skin grafts do not take on bare bone devoid of periosteum, vascularity may be improved by removing a thin layer of exposed cortex in preparation for delayed skin grafting. He used a high-speed steel burr powered by a dermabrasion unit to remove the cortex. ${ }^{1}$

The rationale behind chiseling of the exposed bone is based on accepted concepts of epidermal wound healing. With the wounding of the epithelium, the steady state of the stratified squamous keratinizing epithelium is disrupted, epidermal-cell contact inhibition is lost, and cell migration and reepithelialization begin. ${ }^{6}$ Epidermal regeneration proceeds from the epidermis at the wound margins, the outer root sheaths of hair follicles, and the walls of the ducts 
of apocrine glands. ${ }^{7}$ Therefore, epithelialization is rapid with superficial wounds since cells must migrate only half the distance between appendages to reestablish cell contact. In the full-thickness defect, such as occurs following extensive Mohs surgery, the absence of the appendageal epithelium prolongs the healing time. ${ }^{3}$

Chiseling of exposed bone improves vascularity and provides the wounded area with undifferentiated mesenchymal cells that have the capacity to transform into migratory fibroblasts. When fibroblasts migrate into a wound, they are closely followed by new capillary formation from endothelial budding and the typical picture of a granulating surface appears. The fibroblasts synthesize collagen, mucopolysaccharides, and glycoproteins to form new connective tissue. It is over this tissue that the subsequent migrating epithelial cells pass. ${ }^{8}$

Some fibroblasts develop a rich supply of myofibrils and are referred to as myofibroblasts. ${ }^{3}$ Myofibroblasts appear to be responsible for wound contraction in humans. Depending upon the anatomical circumstances, wound contraction can be either beneficial or detrimental. Facilitation of wound contraction is beneficial for large defects of the upper forehead, as in the case presented. In such cases, healing by secondary intention provides excellent cosmetic results as the wound often contracts in the direction of the anatomic skin tension lines. ${ }^{1}$

The advantages of the technique presented include: simple postoperative wound care; absent donor site pain, scarring, and deformity as might occur with skin grafting; faster healing time than that likely without chiseling; a very acceptable cosmetic result with a good match of color, contour, and texture; and the ability to easily observe the site for recurrence of the tumor. Chiseling of exposed bone to stimulate granulation tissue after extensive Mohs surgery may be considered a useful adjunct to healing in elderly patients or others in whom reconstructive surgery with flaps or grafts is not a feasible closure option.

\section{REFERENCES}

1. Ceilley, R. I., Bumsted, R. M., and Panje, W. R. Delayed skin grafting. J. Dermatol. Surg. Oncol. 9:288-293, 1983.

2. Goldwyn, R. M., and Rueckert, F. The value of healing by secondary intention for sizable defects of the face. Arch. Surg. 112:285-292, 1977.

3. Pollack, S. V. Wound healing: a review. The biology of wound healing. J. Dermatol. Surg. Oncol. 5:389-393, 1979.

4. Mohs, F. E. Chemosurgery: Microscopically Controlled Surgery for Skin Cancer. Springfield (Illinois), Charles C Thomas, 1978, p. 26.

5. Bloom, R. F. Nonrepair of exposed frontal bone after Mohs' surgery for extensive basal cell carcinoma. S. Med. J. 73:971-974, 1980.

6. Martinez, I. R. Fine structural studies of migrating epithelial cells following incision wounds. In: Maibach, H. 1., and Rovee, D. T. (eds.), Epidermal Wound Healing. Chicago, Year Book Medical Publishers, 1972, pp. 323-342.

7. Winter, G. D. Epidermal regeneration studied in the domestic pig. In: Maibach, H. I., and Rovee, D. T. (eds.), Epidermal Wound Healing. Chicago, Year Book Medical Publishers, 1972, pp. 71-112.

8. Peacock, E. E., and Van Winckle, W. Surgery and Biology of Wound Repair. Philadelphia, Saunders, 1970, pp. 15, 91. 